\title{
УРОВНИ, ФАКТОРЫ ПОВЫШЕНИЯ МОТИВАЦИИ В ОБУЧЕНИИ ПСИХОЛОГИИ
}

\author{
Криушинская Галина Владимировна \\ преподаватель \\ гуманитарной кафедры и естественно-научных дисциплин \\ Домодедовского филиала РосНОУ
}

Аннотация: в работе рассмотрены уровни и факторы повышения мотивации студентов по психологии, для эффективного и успешного обучения. Приведены мотивы, способы их применения в процессе психической регуляции деятельности человека. Сгруппированы способы эффективности мотивации у студентов.

Ключевые слова: мотивы, мотивации, обучение, уровни и факторы мотивации.

\section{LEVELS, FACTORS OF INCREASING MOTIVATION IN PSYCHOLOGY TEACHING}

\author{
Kriushinskaya Galina Vladimirovna \\ teacher of the Department of Humanities and Natural Sciences \\ The Domodedovo branch of RosNOU
}

\begin{abstract}
: the work considers the levels and factors of increasing the motivation of students in psychology, for effective and successful learning. Motives, methods of their application in the process of mental regulation of human activity are given. The methods of effective motivation of students are grouped.
\end{abstract}

Key words: motives, motivations, training, levels and motivation factors.

Эффективное обучение лежит через понимание мотивации студентов. Зная то, что движет студентом, что побуждает его к деятельности, какие мотивы лежат в основе его действий, можно попытаться разработать эффективную систему форм и методов управления. Для этого нужно знать, как возникают или вызываются те, или иные мотивы, как и какими способами мотивы могут быть приведены в действие.

Термин «мотивация» имеет разную трактовку. В одном случае её рассматривают как совокупность факторов, поддерживающих и 
направляющих поведение. В другом случае - как совокупность мотивов. В третьем - как побуждение, вызывающее активность организма и определяющее его направленность, т.е. как комплекс факторов, направляющих и побуждающих поведение человека. Кроме того, мотивация рассматривается как процесс психической регуляции конкретной деятельности человека [1]. Весь спектр возможных приемов можно условно разделить на несколько групп в соответствии со сферой их применения.

Акцент на стимулирующее влияние изучаемого материала Встраивая новый материал в уже имеющуюся систему знаний по вашему предмету и другим дисциплинам - так вы покажите их взаимосвязь и важность отдельного элемента в цельной парадигме.

Акцентируйте внимание на актуальности и новизне учебного материала.

- Делайте акцент на раскрытие практической и научной значимости знания.

- Указывайте на профессиональную направленность учебного материала, показывайте, где и как студенты воспользуются полученными знаниями.

Рассмотрим возможные уровни мотивов учебной деятельности в профессиональной школе:

Первый уровень мотивации. Студент, понимая значение изучаемых наук, проявляет интерес к учебному предмету, особенно когда преподаватель устанавливает связи рассматриваемого материала с будущей профессией. В то же время решение задач, выполнение упражнений, написание рефератов не увлекает студента, он стремится избежать такой работы. Его привлекает формальный, простой материал, несложные задания, с помощью которых можно получить зачет или даже сдать экзамен, достигнуть условных успехов без особых усилий и напряжений. Личностные профессионально значимые качества проявляются слабо и не всегда, их профессиональную значимость выявить сложно, скорее всего, мотив учения характеризуется через осознание "надо". [2]. По своему, каждый человек сам себе психолог.

Второй уровень мотивации учебной деятельности отличается достаточной совокупностью всех компонентов мотивации. Студент четко выделяет учебные предметы, которые кажутся ему наиболее важными и интересными. На интересующих его занятиях он активен, самостоятелен, может с помощью преподавателя ставить цели предстоящей учебной деятельности, сознательно стремится овладевать знаниями и умениями, 


\section{ВСЕРОССИЙСКИЙ ИССЛЕДОВАТЕЛЬСКИЙ ФОРУМ

работать организованно, собрано и столько, сколько нужно. Сам процесс учебной и профессиональной деятельности доставляет ему удовольствие, он не отказываются от спецкурсов, внеаудиторных занятий. Однако студент данного уровня мотивации еще нуждаются в руководстве.

Третий уровень мотивации характерно глубокое осознание зависимости своего профессионального становления с психологической точки зрения от всей программы, ярко проявляется познавательная активность, потребность в саморазвитии, становясь постепенно профессиональным психологом.

Факторы (условия), способствующие формированию у студентов положительной мотивации к учению:

- Заинтересованность в ближайших и конечных целей обучения;

- Осознание теоретической и практической значимости усваиваемых знаний; эмоциональная форма изложения учебного материала;

- Показ «перспективных линий» в развитии научных понятий; профессиональная направленность учебной деятельности;

- Выбор заданий, создающих проблемные ситуации в структуре учебной деятельности; вовлечение в учебный план, наличие любознательности и «познавательного психологического климата в учебной группе.

Необходимо также отметить, что мотив является продуктом мотивации, то есть «психической деятельности, конечной целью которой является формирование основания активности человека и побуждения к достижению выбранной цели».

Студент вовлекается в процесс самостоятельного поиска и «открытия» новых знаний, решает задачи проблемного характера.

Мотивация обучения - это направленность студента на различные стороны учебной деятельности. Например, если активность студента направлена на работу с самим изучаемым объектом (лингвистическим, математическим, биологическим и т. д.), то чаще всего в этих случаях можно говорить о разных видах познавательных мотивов. Если активность студента направлена в ходе учения на отношения с другими людьми, то речь идет, как правило, о различных сощииальных мотивах. Иными словами, одних учеников в большей мере мотивирует сам процесс познания в ходе учения, других отношения с другими людьми в ходе учения.

Группы мотивов описаны в психологической литературе. Первая большая группа мотивов может быть разбита на несколько подгрупп: 


\section{ВСЕРОССИЙСКИЙ ИССЛЕДОВАТЕЛЬСКИЙ ФОРУМ

1) широкие познавательные мотивы, состоящие в ориентации обучающихся на овладение новыми знаниями. Они также различаются по уровням. Этот уровень определяется глубиной интереса к знаниям. Это может быть интерес к новым занимательным фактам, явлениям, либо интерес к существенным свойствам явлений, к первым дедуктивным выводам, либо интерес к закономерностям в учебном материале, к теоретическим принципам, к ключевым идеям и т. д.;

2) учебных познавательных мотивов, состоящих в ориентации обучающихся на усвоение способов добывания знаний: интересы к приемам самостоятельного приобретения знаний, к методам научного познания, к способам саморегуляции учебной работы, рациональной организации своего учебного труда;

3) мотивы самообразования, состоящие в направленности обучающихся на самостоятельное совершенствование способов добывания знаний, используя интернет, в том числе.

Эти уровни познавательных мотивов могут обеспечивать наличие у студента так называемого «мотива достижения», который состоит в стремлении студента к успеху в ходе как бы постоянного соревнования с самим собой, в желании добиться новых, все более высоких результатов по сравнению со своими предыдущими результатами [1].

Все эти познавательные мотивы обеспечивают преодоление трудностей обучающихся в учебной работе, вызывают познавательную активность и инициативу, ложатся в основу стремления человека быть компетентным, желания быть «на уровне века», запросов времени и т. д.

Вторая большая группа мотивов - социальные мотивы - также распадается на несколько подгрупп:

1) यирокие сочиальные мотивы, состоящие в стремлении получать знания, чтобы быть полезным Родине, обществу, желании выполнить свой долг, в понимании необходимости учиться и в чувстве ответственности. Студент понимает, почему надо учиться, но это еще может не побуждать его заниматься учебной деятельностью. Здесь велико значение мотивов осознания социальной необходимости, долженствования [2].

2) узкие социильные, так называемые позиционные, состоящие в стремлении занять определенную позицию, место в отношениях с окружающими, получить их одобрение, заслужить у них авторитет. 


\section{ВСЕРОССИЙСКИЙ ИССЛЕДОВАТЕЛЬСКИЙ ФОРУМ

Эти мотивы связаны с широкой потребностью человека в общении, в стремлении получить удовлетворение от процесса общения, от налаживания отношений с другими людьми, от эмоциональных взаимодействий с ними.

Мотивация студентов является одной самых сложных педагогических проблем настоящего. Мотивационными процессами в обучении студентов можно и нужно управлять: создавать условия для развития внутренних мотивов, стимулировать студентов. Как надо мотивировать студента, чтобы его обучение принесло желаемые эффекты и пользу принесло не только ему, а и обществу в целом? Этот вопрос для психологов, педагогов и общества. Время объективно требует изменения роли и место преподавателя в учебном процессе. Студент должен быть действующим лицом, а преподаватель - его партнером, наставником в обучении и развитии [3].

Например, у части студентов младших курсов после первой производственной практики отмечается некоторое разочарование в профессии, потеря интереса к учебе и закономерное снижение профессиональной мотивации.

Снижение уровня профессиональной мотивации у студентов в данном случае, в основном, носит ситуативный характер. В период подготовки к производственной практике отмечается ухудшение функционального состояния, вызванное ожиданием практики, тем самым пропадает интерес к будущей профессии. Представления студентов о предстоящем взаимодействии с персоналом организации вызывают опасения и тревогу у большинства студентов, принявших участие в обследовании. Негативные ожидания от предстоящего взаимодействия с персоналом, необходимость адаптироваться в новом для обучающегося коллективе, представления о реализации задач практики и возможных трудностях провоцируют $\mathrm{y}$ студентов младших курсов «редукцию профессиональных интересов, обесценивание деятельности будущего специалиста и снижение значимости профессиональных компетенций» [3;4].

Необходимо отметить, что профессиональные интересы большинства третьекурсников в большей степени ситуативные и, скорее, связаны с тематикой предметов, изучаемых в текущем семестре, чем являются следствием осознанного профессионального выбора. Поэтому выбор баз практики не должен осуществляться студентами самостоятельно, преимущественно в соответствии с их собственными интересами, без учета специфики контингента, которому предстоит работать на практике. Зачастую 
студенты не идентифицируют деятельность в рамках производственной практики с будущей профессиональной деятельностью, а ведущим мотивом выбора места практики является мотив «испытать» себя в этой роли. Поэтому, мотивационные установки к практической деятельности студентов могут в большей степени определяться ожиданиями от предстоящей практики, а не степенью выраженности их профессиональных компетенций.

У студентов старших курсов, с учетом уже имеющихся знаний, отсутствуют трудности с планированием и структурированием собственной практической деятельности, поэтому они более адаптированы в профессиональной среде. Их в большей степени тревожит возможное несоответствие требованиям, предъявляемым к будущему психологу и недостаточная формулировка профессиональных компетенций. Ревизия собственных личностных качеств и степени сгруппированными практических навыков и теоретико-методологической подготовки может отрицательно сказываться на уровне мотивации к профессиональной деятельности.

Основным мотивом для выбора практики может являться максимальное исключение вероятности демонстрации профессиональной некомпетентности.

Следовательно, мотивационные установки студентов старших курсов в большей степени зависят от их субъективной оценки сформированности профессиональных компетенций и экспертных оценок.

\section{Список литературы}

1. Ильин Е. П.. Мотивация и мотивы. - СПб.: Питер,- 512 с: ил. (Серия «Мастера психологии») 2002.

2. Королева О. А. Особенности мотивации студентов к обучению // Человек, экономика, общество: грани взаимодействия : сборник научных трудов по материалам Международной научно-практической конференции 28 декабря 2019г. : Белгород : ООО Агентство перспективных научных исследований (АПНИ), 2019. URL: https://apni.ru/article/217-osobennostimotivatsii-studentov-k-obucheniyu

3. Лисовец Н.M. Профессиональная мотивация студентов как способ активации обучения http://b.slave.festival.1 september.ru/articles/598947/

4. Маркова А.К. Формирование мотивации учения в школьном возрасте: пособие для учителя. А.К. Маркова. - М.: Просвещение, 2014. - 96 с. 